\title{
A Point in the History of Contemporary Thyroid Surgery
}

\author{
Sohail Bakkar ${ }^{1 *}$, Liliana Pezzetta ${ }^{2}$, Ayman Mismar $^{3}$, Malince Chicas $^{4}$ \\ ${ }^{1}$ Department of Surgical Pathology, Division of Endocrine Surgery, University Hospital of Pisa, Via Paradisa 2, 56124 Pisa, Italy \\ ${ }^{2}$ Department of General Surgery, Hospital Universitario de Canarias, Canary Islands, Spain \\ ${ }^{3}$ Department of Surgery, Faculty of Medicine, Jordan University, Amman, Jordan \\ ${ }^{4}$ Hospital General del ISSS Alameda Juan Pablo II y 25 Ave Norte, San Salvador, El Salvador
}

\begin{abstract}
Received: 25 August, 2016; Accepted: 12 September, 2016; Published: 22 September, 2016
*Corresponding author: Sohail Bakkar, Department of Surgical Pathology, Division of Endocrine Surgery, University Hospital of Pisa, Via Paradisa2, 56124 Pisa, Italy, Tel no: + 393441162487, Fax no: + 39050997709; E-mail: sohail.bakkar@gmail.com
\end{abstract}

Our purpose here is to highlight a turning point in the history of thyroid surgery, and emphasize that recognizing and appreciating the input of others is a major contributor to the continuing prosperity of the science and art of surgery.

The transition from the bloody and festering time for thyroid surgery (the mid $19^{\text {th }}$ century) to the time where thyroid surgery was considered extremely safe and efficient (mid $20^{\text {th }}$ century) was mainly attributed to the work of seven pioneers often referred to in literature as "the magnificent seven" [1]. These were Theodor Billroth, Theodor Kocher, William Halsted, Charles Mayo, George Crile, Frank Lahey and Thomas Dunhill. Kocher is considered the "father of thyroid surgery". The principles he described revolutionized thyroid surgery and earned him the Nobel Prize in Medicine and Physiology in 1909 [1].Similar work of pioneers of our era was behind the birth and evolution of minimal access surgery (MAS). The door to MAS was opened by two gifted individuals: a scientist and a precision instrument maker. Professor Harold Hopkins (19181994), a renowned British physicist, introduced the rigid rod lens system in 1959. Karl Storz, a German manufacturer of precision medical instruments, took the commercial risk of putting it into production and added the fiberoptic light transmission system [2]. A major contributor to the advancement of MAS for thyroid pathologies was the work of Professor Paolo Miccoli; an Italian Surgeon who developed and popularized the most widely spread endoscopic thyroidectomy performed today; the minimally invasive video-assisted thyroidectomy (MIVAT) [3].

At first glance, one would think that the importance of minimal access thyroid surgery arises solely from the fact that the majority of patients are young women who may be equally concerned about therapeutic and cosmetic outcomes, and that the contemporary endocrine surgeon needs to offer patients a surgical approach that is tailored to their concerns and desires. Such a view is probably further reinforced by the development of various remote-access procedures that offer patients thyroid surgery free of a neck scar. Remote-access thyroid surgery despite being optimal in conserving the patient's body image [4], exemplifies where the concepts of a minimal access and minimal invasiveness clash [5, 6]. The true essence of minimal invasiveness is related to a direct access and a targeted dissection; factors lacking in remote-access surgery as implied by its name. Furthermore, the absence of these same factors potentially jeopardizes the balance between therapeutic and cosmetic outcomes in favor of the latter. This is particularly significant in the context of malignant disease where it is crucial to adhere to the fundamental onco-surgical principles that state: local control is a top priority and a direct-access is critical for that [7].

Miccoli is a pioneer and a visionary who acknowledged early on that while tailoring the surgical strategy undertaken to patients' concerns and desires is important for the contemporary Endocrine Surgeon, adhering to fundamental onco-surgical principles of safety is a priority. The birth of MIVAT was the result of this vision. Like any other novel procedure, MIVAT was initially surrounded by doubt. However, the contributions of Miccoli et al. unveiled a revolutionary procedure that combined the concepts of minimal access, minimal invasiveness, safety, and effectiveness $[8,9]$. MIVAT became a surgical tool for all types of thyroid pathologies [10]. The prosperous impact of his work on the evolution of thyroid surgery is a constant reminder of Billroth's saying; "Only a man who is familiar with the art and science of the past is competent to aid in its progress in the future" [11]. Miccoli's work and devotion to the science and art of surgery, and his commitment to evidence-based surgical innovation should be recognized as a feather in his cap. A procedure he developed and popularized almost two decades ago continues to top the list of minimal access and minimally invasive thyroid surgery.

\section{Disclosure}

The authors were mentored by Professor Miccoli during either their sub specialization training in Endocrine Surgery (SB and AM) or a period of clinical attachment (LP and MV).

\section{References}

1. Hannan SA. The magnificent seven: a history of modern thyroid surgery. Int J Surg. 2006;4(3):187-191.

2. Linder TE, Simmem D, Stool SE. Revolutionary inventions in the 20th century. The history of endoscopy. Arch Otolaryngol Head Neck Surg. 1997;123(11):1161-1163. 
3. Bakkar S, Materazzi G, Biricotti M, De Napoli L, Conte M, Galleri D, et al. Minimally invasive video-assisted thyroidectomy (MIVAT) from A to Z. Surg Today. Surg Today. 2016;46(2):255-259. doi: 10.1007/ s00595-015-1241-0.

4. Materazzi G, Fregoli L, Manzini G, Baggiani A, Miccoli M, Miccoli P. Cosmetic results and overall satisfaction after minimally invasive video-assisted thyroidectomy (MIVAT) versus robot-assisted transaxillary thyroidectomy (RATT): a prospective randomized study. World J Surg. 2014;38(6):1282-1288. doi: 10.1007/s00268-0142483-5.

5. Henry JF. Minimally invasive thyroid and parathyroid surgery is not a question of the length of the incision. Langenbecks Arch Surg. 2008;393(5):621-6. doi: 10.1007/s00423-008-0406-3.

6. Tan CT, Cheah WK, Delbridge L. "Scarless" (in the neck) endoscopic thyroidectomy (SET): an evidence-based review of published techniques. World J Surg. 2008;32(7):1349-1357. doi: 10.1007/ s00268-008-9555-3.

7. Bakkar S, Frustaci G, Papini P, Fregoli L, Matteucci V, Materazzi G, et al. Track Recurrence after Robotic Transaxillary Thyroidectomy:
A Case Report Highlighting the Importance of Controlled Surgical Indications and Addressing Unprecedented Complications. Thyroid. 2016;26(4):559-561. doi: 10.1089/thy.2015.0561.

8. Zheng C, Liu S, Geng P, Zhang H, Zhang H, Tang A, et al. Minimally invasive video-assisted versus conventional open thyroidectomy on immune response: a meta analysis. Int J Clin Exp Med. 2015;8(2):25932599.

9. Pisanu A, Podda M, Reccia I, Porceddu G, Uccheddu A. Systematic review with meta-analysis of prospective randomized trials comparing minimally invasive video-assisted thyroidectomy (MIVAT) and conventional thyroidectomy (CT). Langenbecks Arch Surg. 2013;398(8):1057-1068. doi: 10.1007/s00423-013-1125-y.

10. Miccoli P, Biricotti M, Matteucci V, Ambrosini CE, Wu J, Materazzi G. Minimally invasive video-assisted thyroidectomy: reflections after more than 2400 cases performed. Surg Endosc. 2016; 30(6):24892495. doi: 10.1007/s00464-015-4503-4.

11. Ferlito A, Johnson JT, Rinaldo A, Pratt LW, Fagan JJ, Weir N, et al. European surgeons were the first to perform neck dissection. Laryngoscope. 2007;117(5):797-802. 